\title{
Platelet Binding Characteristics Distinguish Placebo Responders from Nonresponders in Depression
}

Yvette I. Sheline, M.D., Kevin J. Black, M.D., Mark E. Bardgett, Ph.D., and John G. Csernansky, M.D.

To determine whether there are characteristics distinguishing placebo responders from nonresponders, we studied 37 outpatients meeting DSM-III-R criteria for depression who were enrolled in controlled drug trials and 14 control subjects. Clinical data and blood samples were collected on admission and after a 7- to 10-day placebo washout. All patients experiencing a $40 \%$ drop in the Hamilton Rating Scale for Depression (HRSD) at the time of the second evaluation were considered placebo responders. There were no statistically significant differences between the two groups in clinical variables. Platelet markers distinguished the groups: Most notably, placebo nonresponders had the lowest 5-HT uptake site density values, placebo responders had intermediate values, and normal controls had the highest values. Placebo responders and placebo nonresponders had higher 5-HT uptake affinity values. No significant differences were observed among the groups in platelet $5-\mathrm{HT}_{2}$ receptor site density or affinity values. These results suggest that platelet serotonin characteristics, but not common clinical characteristics, may distinguish depressed patients who do and do not respond to placebo. [Neuropsychopharmacology 12:315-322, 1995]

sponse in depression. The general approach to accounting for placebo response in clinical trials has been to subtract it from the rate of active response to obtain a rate of "true" antidepressant response (Quitkin et al. 1984). It has also become common practice to include an initial 7- to 10-day single-blind placebo "washout" for depressed patients after baseline assessment to eliminate as many early responders to placebo as possible. Initial placebo washouts may identify patients who are quickly affected by the act of pill taking, the expectation of getting well, and the attention and support received during assessment in a clinical trial, none of which are due to an active pharmacological agent. A recent study, however, suggests that having a placebo run-in for antidepressant trials does not change the postrandomization drug response rates (Trivedi and Rush 1994). Few studies have examined the characteristics of patients who respond to placebo during the initial washout time period to see whether they might have been identifiable beforehand.
From Washington University School of Medicine in St. Louis Department of Psychiatry, 4940 Children's Place, St. Louis, Missouri 63110.

Address correspondence to: Yvette Sheline, M.D., Assistant Professor of Psychiatry, Department of Psychiatry, Washington University School of Medicine, 4940 Children's Place, St. Louis, MO 63110-1093.

Received April 11, 1994; revised November 4, 1994; accepted November 11, 1994. 
Rabkin et al. (1987) found that washout placebo responders differed from nonresponders in being less depressed at baseline. However, the average severity as assessed by Hamilton Rating Scale for Depression (HRSD) total scores was fairly low - 14.3 in the placebo responder group and 15.6 in the placebo nonresponder group. In contrast, Zammit et al. (1988) found no clinical differences, including in severity, between patients who responded to placebo at 10 days and those who did not. In this latter study placebo nonresponders tended more often to be dexamethasone suppression test (DST) nonsuppressors and to have decreased sleep time.

In this study we sought to identify selected clinical and biochemical predictors that might distinguish placebo responders from nonresponders in a prospective study of unmedicated outpatients who met DSM-III-R criteria for unipolar major depression. Because serotonin dysfunction has been implicated in the pathophysiology of mood disorders (Meltzer and Lowy 1987), we studied platelet 5-HT uptake site and the $5-\mathrm{HT}_{2}$ receptor measurements as well as clinical characteristics. A large literature exists related to platelet 5-HT uptake site density and $5-\mathrm{HT}_{2}$ receptor density abnormalities in depressed patients compared to normals (reviewed in Arora and Meltzer 1989; Biegon et al. 1990; Bunney et al. 1986). In most studies, depressed patients have been shown to have lower 5-HT uptake site density values and higher $5-\mathrm{HT}_{2}$ receptor density values than normal controls. In view of recent findings that the amino acid sequences of the 5-HT transporter (Lesch et al. 1993; Ramamoorthy et al. 1993) and of the 5-HT $2_{\mathrm{a}}$ receptor (Cook et al. 1994) expressed in platelets are the same as those expressed in central 5-HT neurons, relationships found between platelet markers and depression may be valid for understanding central mechanisms. This notion is supported by observations of reduced $B_{\max }$ values for ${ }^{3} \mathrm{H}$-imipramine binding in the frontal cortex of suicide victims (Gross-Isseroff et al. 1989; Stanley et al. 1982).

\section{METHODS}

\section{General Sample}

Patients were recruited through local newspaper advertisements to participate in clinical antidepressant drug trials of various kinds and in a separate research protocol to study platelet serotonin markers in depression. In addition, we studied 14 normal control subjects. Thirty-four patients gave written informed consent. All patients were interviewed by board-certified and specially trained research psychiatrists and met DSM-III-R inclusionary and exclusionary criteria for unipolar major depression. Patients and controls were excluded if, for 3 weeks prior to admission, they had been on any psychotropic drug or any drug with known effects on mood (e.g., benzodiazepines and betablockers). All patients were interviewed and rated using the 17-item HRSD (Hamilton 1960) on admission to the study and after a 7- to 10-day placebo washout. Patients were also rated using the Montgomery-Asberg Depression Rating Scale (MADRS) (Montgomery and Asberg 1979) at the same times as the HRSD. Family history of affective disorder was obtained by interview with patients. Patients were asked if there was any known history of affective disorder in first-degree relatives; no additional interviews were undertaken with family members.

Patients who experienced a $40 \%$ drop in the total HRSD score at the time of the second evaluation were defined a priori as placebo responders. We elected to use a somewhat smaller percentage drop in HRSD $(40 \%$ rather than $50 \%$ ) than other groups have used (Brown et al. 1991; Khan et al. 1991; Rabkin et al. 1987) since our patients are exclusively self-referred outpatients. Figure 1 shows the changes in total HRSD scores of placebo responders and nonresponders from time 1 to time 2. On admission (time 1) placebo nonresponders and placebo responders had respective mean HRSD scores of $24.6 \pm 3.9(\mathrm{SD})$ and $23.5 \pm 1.8(\mathrm{SD})$. After

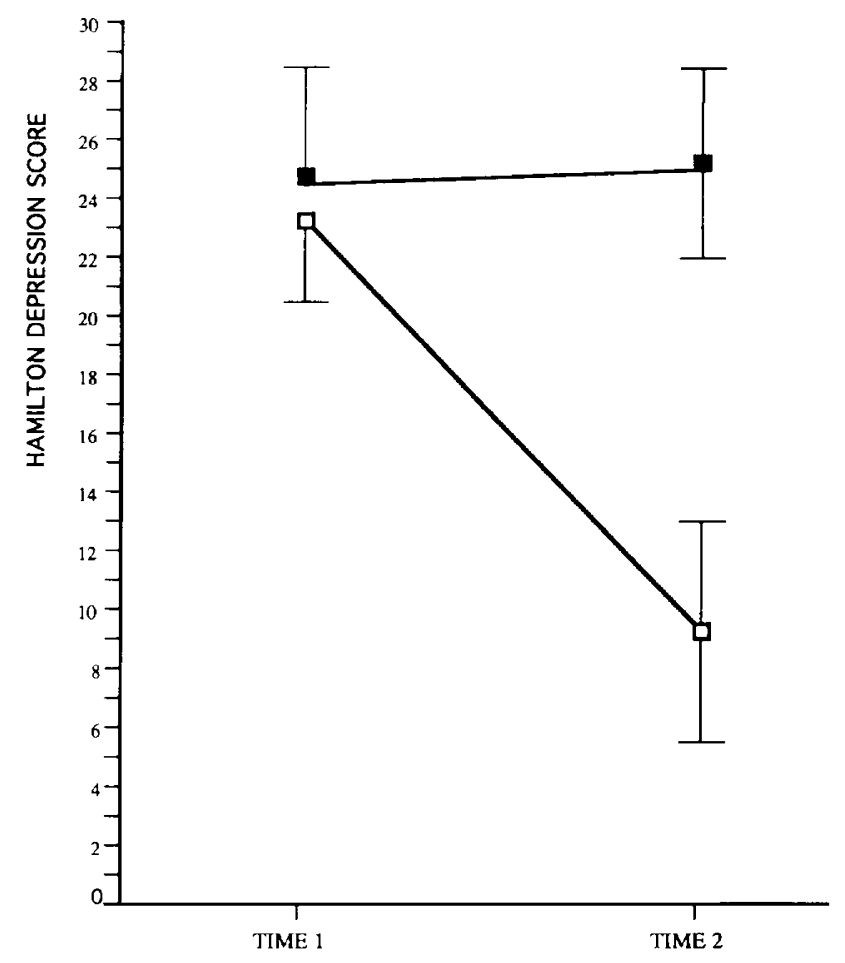

Figure 1. Total HRSD scores of placebo responders (blank squares) and placebo nonresponders (solid squares) on admission to the study (time 1) and after 7 to 10 days of placebo washout (time 2). 
washout (time 2) placebo nonresponders and placebo responders had respective mean HRSD scores of $25.3 \pm$ $3.1(\mathrm{SD})$ and $9.2 \pm 3.9(\mathrm{SD})$.

\section{Platelet Samples}

In 12 patients platelets were collected at the end of a 7- to 10-day placebo washout period. In 21 patients platelets were collected on admission to the study. In 4 patients no platelets were collected ( 3 of the 13 patients who were later found to be placebo responders and one patient who was a placebo nonresponder). In all cases, reported HRSD scores were obtained on the same day on which platelets were harvested.

In order to include as many patients in this study as possible, we included all the patients described after determining whether platelet values were similar when obtained on admission to the study and repeated after a placebo washout phase in a selected subset of patients. Paired $t$-tests were conducted for 12 patients whose platelets had been obtained both on admission and again after placebo washout. No statistically significant differences for 5-HT uptake site densities were found (paired $t$-value $=0.6 ; p=.54$ ). The mean admission value was $994.2 \mathrm{fmoles} / \mathrm{mg}$ protein \pm 235.4 (SD). The mean washout value was $1066.1 \mathrm{fmoles} / \mathrm{mg}$ protein $\pm 520.1(\mathrm{SD})$. Moreover, 5-HT uptake site density values from the two time points were highly correlated among the 12 patients $(r=0.8 ; p<.005)$. For platelet $5-\mathrm{HT}_{2}$ receptor values there was a statistically significant difference between values obtained on admission and after washout (paired $t$-value $=2.4 ; p=$ .04 ) and a poor correlation between density values at the two time points was found $(r=0.3 ; p=\mathrm{NS})$. On admission mean $5-\mathrm{HT}_{2}$ was 39.4 fmoles $/ \mathrm{mg}$ protein \pm 26.8 (SD), whereas after washout it was $61.0 \pm 30.0$. For one patient in each group, the ${ }^{125}$ I-LSD binding assay failed. For one patient in the placebo nonresponder group, the ${ }^{3} \mathrm{H}$-paroxetine binding assay failed (see Table 1).

Platelet Preparation. Platelets were prepared according to a standard protocol as follows: $15 \mathrm{ml}$ of blood was collected by venipuncture from each subject into vacutainers containing $0.3 \mathrm{ml}$ of $7.5 \%$ EDTA ( $\mathrm{pH} 7.5$ ). Centrifugation of the blood occurred at $900 \mathrm{rpm}$ for 10 minutes at $22^{\circ} \mathrm{C}$ in an IEC Centra-8R centrifuge to yield platelet-rich plasma (PRP). The PRP was removed using a plastic pipet, divided into three tubes, and recentrifuged at $3,400 \mathrm{rpm}$ for 15 minutes. The supernatant was then separated from each platelet pellet. The pellet was resuspended in $2 \mathrm{ml}$ of saline glucose buffered with phosphate to a $\mathrm{pH}$ of 7.2 and centrifuged at 3,400 rpm for 15 minutes. Then the supernatant was discarded, and the platelet pellets were immediately frozen at $-70^{\circ} \mathrm{C}$ for storage until analysis.

5-HT $T_{2}$ Receptors (125I-LSD Binding Assay). Frozen platelet pellets were resuspended in $5 \mathrm{ml}$ of $5 \mathrm{mM}$ Tris containing $0.1 \%$ EDTA ( $\mathrm{pH} 7.5$ ). The suspension was homogenized using a Teflon pestle and glass homogenization tube. The homogenate was centrifuged at $50,000 / \mathrm{g}$ for 15 minutes at $4^{\circ} \mathrm{C}$. The pellet was again resuspended in $2.5 \mathrm{ml}$ of ice-cold incubation buffer containing $50 \mathrm{mM}$ Tris, $120 \mathrm{mM} \mathrm{NaCl}, 5 \mathrm{mM} \mathrm{KCl}, 2 \mathrm{mM}$ $\mathrm{MgCl}, 0.05 \%$ ascorbic acid (pH 7.3), and this suspension was rehomogenized. Using the BioRad Protein Assay, protein concentrations were determined with bovine gamma globulin as the standard. Specific binding

Table 1. Placebo Responders (PR) versus Nonresponders (PNR)-Platelet Measures

\begin{tabular}{|c|c|c|c|c|c|}
\hline Predictor & $\begin{array}{c}\mathrm{PR}(n=10)^{a} \\
( \pm \mathrm{SD}) \\
\end{array}$ & $\begin{array}{c}\text { PNR }(n=23)^{a, b} \\
( \pm \mathrm{SD})\end{array}$ & $\begin{array}{c}\text { NC }(n=14)^{a} \\
( \pm S D)\end{array}$ & $F$ Value & $p$ Value \\
\hline $\begin{array}{l}\text { 5-HT uptake site density } \\
\text { (fmoles/mg protein) }\end{array}$ & $\begin{array}{l}1084.3 \\
(478.6)\end{array}$ & $\begin{array}{c}801.3 \\
(268.2)\end{array}$ & $\begin{array}{l}1175.7 \\
(457.0)\end{array}$ & 4.6 & 0.02 \\
\hline $\begin{array}{l}\text { 5-HT uptake site density } \\
\text { (standardized residuals) }\end{array}$ & $\begin{array}{c}0.29 \\
(1.22)\end{array}$ & $\begin{array}{c}-0.42 \\
(0.59)\end{array}$ & $\begin{array}{c}0.48 \\
(0.99)\end{array}$ & 4.8 & 0.01 \\
\hline $\begin{array}{l}\text { 5- } \mathrm{HT}_{2} \text { receptor density } \\
\text { (fmoles/mg protein) }\end{array}$ & $\begin{array}{c}37.7 \\
(24.4)\end{array}$ & $\begin{array}{c}34.1 \\
(21.2)\end{array}$ & $\begin{array}{l}26.6 \\
(15.4)\end{array}$ & 0.91 & 0.41 \\
\hline $\begin{array}{l}\text { 5- } \mathrm{HT}_{2} \text { receptor density } \\
\text { (standardized residuals) }\end{array}$ & $\begin{array}{r}-0.007 \\
(0.97)\end{array}$ & $\begin{array}{c}0.084 \\
(1.14)\end{array}$ & $\begin{array}{l}-0.13 \\
(0.60)\end{array}$ & 0.20 & 0.82 \\
\hline $\begin{array}{l}\text { 5-HT uptake affinity } \\
\text { (nM) }\end{array}$ & $\begin{array}{l}0.77 \\
(0.33)\end{array}$ & $\begin{array}{c}0.59 \\
(0.27)\end{array}$ & $\begin{array}{c}0.24 \\
(0.08)\end{array}$ & 15.1 & 0.0001 \\
\hline $\begin{array}{l}\text { 5-HT uptake affinity } \\
\text { (standardized residuals) }\end{array}$ & $\begin{array}{l}0.75 \\
(1.0)\end{array}$ & $\begin{array}{c}0.19 \\
(0.84)\end{array}$ & $\begin{array}{c}-0.83 \\
(0.18)\end{array}$ & 12.8 & 0.0001 \\
\hline $\begin{array}{l}\text { 5- } \mathrm{HT}_{2} \text { receptor affinity } \\
(\mathrm{nM})\end{array}$ & $\begin{array}{c}0.59 \\
(0.33)\end{array}$ & $\begin{array}{l}0.60 \\
(0.41)\end{array}$ & $\begin{array}{c}0.40 \\
(0.21)\end{array}$ & 1.47 & 0.24 \\
\hline $\begin{array}{l}\text { 5- } \mathrm{HT}_{2} \text { receptor affinity } \\
\text { (standardized residuals) }\end{array}$ & $\begin{array}{c}0.15 \\
(0.81)\end{array}$ & $\begin{array}{c}-0.006 \\
(1.18)\end{array}$ & $\begin{array}{c}-0.09 \\
(0.62)\end{array}$ & 0.17 & 0.84 \\
\hline
\end{tabular}

${ }^{a}$ For $5-\mathrm{HT}_{2}$ values (due to missing data): $n=9$ for placebo responders, $n=13$ for normal controls, $n=22$ for placebo nonresponders.

${ }^{b}$ For 5 -HT uptake values (due to missing data), $n=22$ for placebo nonresponders. 
of ${ }^{125}$ I-LSD (NEN Dupont) was determined at sixligand concentrations $(0.06-1.2 \mathrm{nM})$ in the presence and absence of $1 \mathrm{mM}$ spiperone (Research Biochemicals, Inc.) to control for nonspecific binding. Incubations were performed in microcentrifuge tubes and contained $80 \mathrm{ml}$ of platelet suspension, consisting of $10 \mathrm{mg}$ protein, $10 \mathrm{ml}$ incubation buffer or spiperone, and $10 \mathrm{ml}$ ${ }^{125} \mathrm{I}$-LSD. Tubes were incubated at $37^{\circ} \mathrm{C}$ for 2 hours. The incubations were stopped by the addition of $1 \mathrm{ml}$ of ice-cold Tris/BSA buffer containing $50 \mathrm{mM}$ Tris, $0.01 \%$ bovine serum albumin ( $\mathrm{pH} 7.7$ ). The incubation mixture was then filtered through Whatman GF/B filters using a Brandel cell harvester. Filters were rinsed twice with $4 \mathrm{ml}$ of ice-cold Tris/BSA buffer and placed in 12 $\times 75-\mathrm{mm}$ tubes for gamma counting. To determine density $\left(B_{\max }\right)$ and dissociation constant $\left(K_{\mathrm{D}}\right)$ values, data from platelet binding assays were transformed by Scatchard analysis (EBDA-LIGAND software, ElsevierBiosoft, U.K.), yielding linear plots.

5-HT Uptake Sites ( ${ }^{3}$ H-Paroxetine Binding Assay). Platelet suspensions were prepared as described above, and the protein concentrations were predetermined using the BioRad Assay. Specific binding of ${ }^{3} \mathrm{H}$-paroxetine (NEN-Dupont) was determined at six-ligand concentrations ranging from 0.05 to $1.0 \mathrm{nM}$ in the presence and absence of $1 \mathrm{mM}$ fluoxetine (Eli Lilly and Co.) to control for nonspecific binding. The incubation mixtures consisted of platelet suspensions each containing $20 \mathrm{mg}$ protein, $10 \mathrm{ml}$ incubation buffer or fluoxetine, $10 \mathrm{ml}$ ${ }^{3} \mathrm{H}$-paroxetine, and sufficient incubation buffer to bring the total volume to $1 \mathrm{ml}$. Incubations were performed in $12 \times 75-\mathrm{mm}$ polypropylene tubes. Following incubation for 20 minutes at $37^{\circ} \mathrm{C}$, the samples were rapidly filtered through prewetted Whatman GF/B filters. Filters were rinsed and counted, and the data were analyzed as described. In keeping with prior observations that ligand binding to the serotonin transporter protein is $\mathrm{Na}^{+}$-dependent (Marcusson and Ross $1990)$, the binding of $0.3 \mathrm{nM}{ }^{3} \mathrm{H}$-paroxetine $(n=6)$ was reduced to negligible levels $(<5 \%)$ in the absence of $\mathrm{Na}^{+}$.

Data Analyses. Multiple regression analyses were used to obtain standardized residual values for 5-HT uptake site density and $5-\mathrm{HT}_{2}$ receptor density in order to assess the effects of these variables independently of other related variables (e.g., age, 5-HT uptake, and $5-\mathrm{HT}_{2}$ receptor affinity values). Multiple regression analyses were also used to derive standardized 5-HT receptor uptake affinity residual values and standardized $5-\mathrm{HT}_{2}$ receptor affinity residual values. The model to produce standardized 5-HT uptake site density residuals did not achieve statistical significance $(r=$ $0.4 ; F=1.8 ; p=.15$, including the following independent variables: age, 5-HT uptake site affinity, 5- $\mathrm{HT}_{2}$ receptor density, and $5-\mathrm{HT}_{2}$ affinity). The model to produce standardized $5-\mathrm{HT}_{2}$ receptor density residuals did achieve statistical significance $(r=0.65 ; F=6.9$; $p=.0003$, including the following independent variables: age, 5-HT uptake site affinity, $5-\mathrm{HT}_{2}$ receptor density, and $5-\mathrm{HT}_{2}$ affinity). The model to produce standardized $5-\mathrm{HT}_{2}$ affinity values was also statistically significant ( $r=0.7 ; F=7.4 ; p=.0002$ ). The model to produce standardized 5-HT uptake affinity values was not statistically significant $(p=.95$, including the following independent variables: age, 5-HT uptake site affinity, $5-\mathrm{HT}_{2}$ receptor density, and $5-\mathrm{HT}_{2}$ affinity).

Comparisons were made on age, sex, MADRS score, HDRS score, melancholia, history of major depression in first-degree relatives, previous history of depression, previous treatments with medication, duration of current episode, interval off psychotropic medication prior to placebo washout, and history of nonresponse to previous treatment. Between-group comparisons were conducted using $x^{2}$ or unpaired $t$-tests for categorical and numerical variables, respectively. $P$-values shown are uncorrected for multiple comparisons. Comparisons of platelet variables among three groups were conducted using one-way analysis of variance (ANOVA). Both raw values and standardized residuals (derived as described above) were compared among the groups. For ANOVAs that achieved statistical significance, post hoc betweengroup comparisons were made using Fisher's protected least squares difference (PLSD) to determine significance at the .05 level. Pearson correlations were estimated to evaluate continuous bivariate relationships, using $p<.05$ as the criterion for statistical significance.

\section{RESULTS}

Table 2 summarizes the demographic characteristics of the patient samples and matched control sample. There were no statistically significant differences between placebo responders and placebo nonresponders with regard to clinical characteristics, including age, gender, history of depression in first-degree relatives, melancholia, age at depression first onset, prior treatment for depression, duration of current episode, interval off psychotropic medication prior to placebo washout, total HRSD score, or total MADRS score, although there were trends for total $\operatorname{HRSD}(p=.052)$ and history of non-response to previous treatment $(p=.08)$.

Table 1 compares platelet 5-HT variables from placebo responders, placebo nonresponders, and normal controls. As further illustrated in Figure 2, differences were observed in platelet 5-HT uptake-site density values. Placebo nonresponders had the lowest $5-\mathrm{HT}$ uptake density. Placebo responders had intermediate values, and normal controls had the highest values. A post hoc two-way comparison between placebo non- 
Table 2. Placebo Responders (PR) versus Placebo Nonresponders (PNR)Clinical Comparison

\begin{tabular}{|c|c|c|c|c|}
\hline & $\begin{array}{c}\text { PR } \\
(n=13)\end{array}$ & $\begin{array}{c}\text { PNR } \\
(n=24)\end{array}$ & $\begin{array}{l}t \text { or } \chi^{2} \\
\text { Value }\end{array}$ & $p$ Value \\
\hline Age & 41.3 & 43.2 & 0.39 & 0.70 \\
\hline $\operatorname{Sex}(m / f)$ & $7 / 6$ & $7 / 17$ & 2.2 & 0.14 \\
\hline MADRS & 29.2 & 29.7 & 0.27 & 0.79 \\
\hline HRSD & 23.4 & 25.3 & 2.02 & 0.052 \\
\hline Melancholia $(\mathrm{y} / n)$ & $4 / 9$ & $11 / 13$ & 0.79 & 0.37 \\
\hline Family history $(\mathrm{y} / n)^{\mathrm{a}}$ & $8 / 4$ & $17 / 6$ & 0.2 & 0.65 \\
\hline First episode $(y / n)$ & $2 / 11$ & $4 / 20$ & 0.01 & 0.92 \\
\hline Duration in months & & & 0.06 & 0.97 \\
\hline $1-3$ & 2 & 3 & & \\
\hline 3-6 & 2 & 4 & & \\
\hline$>6$ & 9 & 17 & & \\
\hline Medication ever given $(y / n)$ & $5 / 8$ & $13 / 11$ & 0.83 & 0.57 \\
\hline Interval off medication (weeks) & $\begin{array}{c}21.6 \\
(n=5)\end{array}$ & $\begin{array}{c}19.6 \\
(n=13)\end{array}$ & 0.38 & 0.71 \\
\hline History of nonresponse $(\mathrm{y} / n)$ & $0 / 13$ & $5 / 19$ & 3.13 & 0.08 \\
\hline
\end{tabular}

\footnotetext{
${ }^{a}$ There was one missing value in both placebo responder and placebo nonresponder groups be-
} cause of the adopted status of two patients.

responders and normal controls was also significant (Fisher's PLSD $p<.05$ ). Standardized residual values for 5-HT uptake density also yielded statistically significant differences between normal controls and placebo nonresponders (Fisher's PLSD $p<.05$ ) and between placebo nonresponders and placebo responders (Fisher's PLSD $p<.05$ ); whereas there was not a significant difference between normal controls and placebo responders.

Statistically significant differences were observed among the three groups for platelet 5-HT uptake affinity values, with placebo responders and placebo nonresponders having higher 5-HT uptake affinity values than normal controls. Standardized residual values for 5-HT uptake affinity were also significantly different among the groups. Between-group comparisons were statistically significant between normal controls and placebo nonresponders and between normal controls and placebo responders (Fisher's PLSD $p<0.05$ in both cases), but not between placebo responders and placebo nonresponders.

There were no statistically significant differences

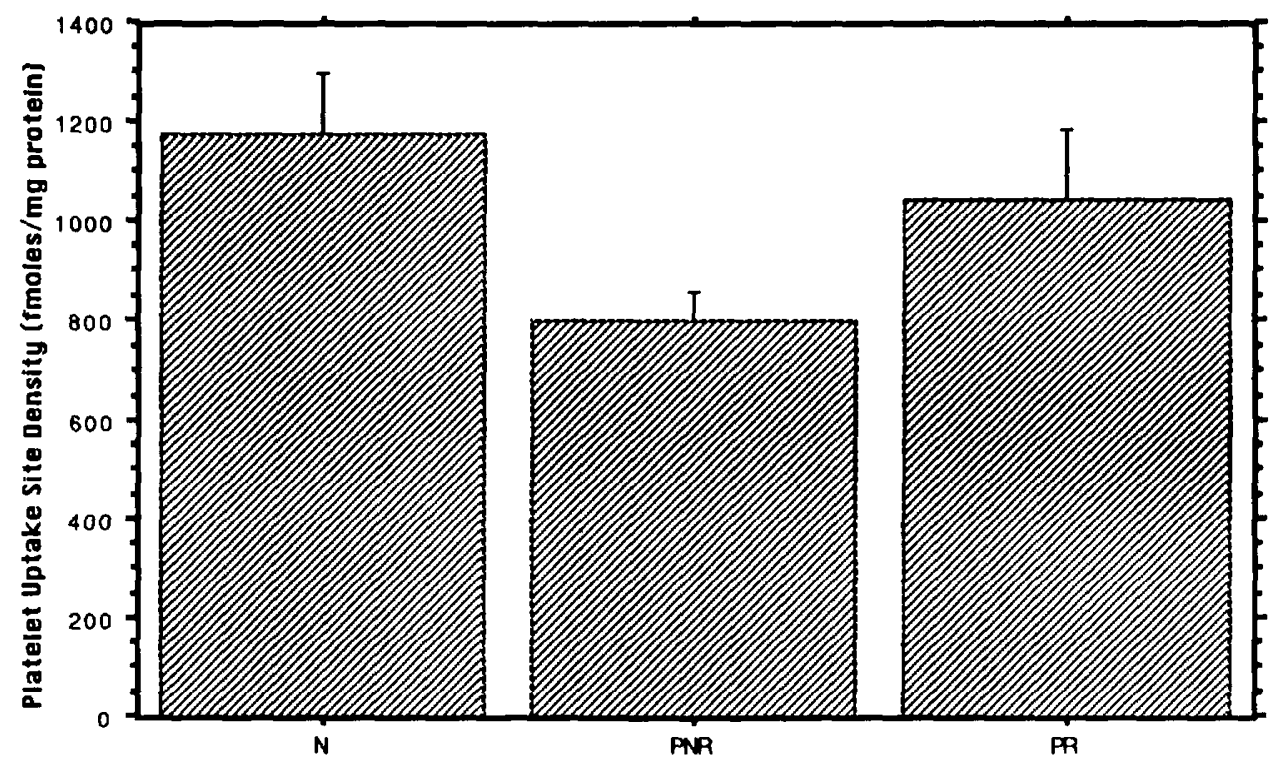

Subject Category
Figure 2. Platelet 5-HT uptake site density $\left(B_{\max }\right)$ in fmoles/mg protein in placebo nonresponders (PNR), placebo responders (PR), and normal control $(\mathrm{N})$ subjects. 
in platelet $5-\mathrm{HT}_{2}$ receptor affinity or density (raw values or standardized residuals) among the groups.

\section{DISCUSSION}

To our knowledge, this is the first report of differences in platelet markers between depressed patients who are placebo responders and nonresponders. Although Freeman et al. (1993) described differences in platelet ${ }^{3} \mathrm{H}$-imipramine binding sites between "fast" and "slow" antidepressant drug responders, it was not known in fact which of these patients were treated with placebo. There is a large literature describing differences in brain and platelet serotonin function between patients with depression and normal controls (Mann et al. 1992; Meltzer and Lowy 1987). We have previously shown correlations between specific symptom domains of depression (guilt, suicidal thinking, etc.) and measurements of 5-HT functioning as evidenced by platelet 5-HT uptake site density values (Sheline et al. 1995) and by cerebrospinal fluid (CSF) 5-hydroxy-indole-acetic acid (5-HIAA) levels (Faustmann et al. 1990).

In prior studies implicating serotonin pathophysiology in mood and behavioral disturbance, the observed differences were between acutely depressed patients and normal controls. However, in the current study both placebo responders and placebo nonresponders were acutely depressed at the time that platelets were obtained, with similar severity of symptoms as measured by the HRSD and MADRS. Although the twopoint difference in total HRSD scores approaches statistical significance, we do not consider it to be clinically significant, and we have previously shown no significant correlation between platelet markers and total HRSD (Sheline et al. 1995). Furthermore, mean baseline HRSD scores (24.6 for placebo nonresponders, 23.5 for placebo responders, $p=.38$ ) were even more similar. It is therefore unlikely that the differences in platelet marker measurements between placebo responders and placebo nonresponders in the current study were due to differences in the degree of depression, suggesting that other factors, perhaps inherent biological differences, are more important in distinguishing between the two groups.

We were not able to demonstrate clinical differences between the two groups other than a trend toward a difference in response to previous treatment as has also been reported by Brown et al. (1992); however, our sample size was admittedly small. Other groups have reported that placebo response in depressed patients is associated with clinical characteristics including the presence of a precipitating event (Brown et al. 1992), less chronicity (Brown et al. 1992; Fairchild et al. 1986; Khan et al. 1991); comorbidity with personality dis- orders and anxiety disorders (Fairchild et al. 1986), and less melancholia (Peselow et al. 1992).

In our study we also replicated the common finding that 5-HT uptake-site density values differed between at least some patients with depression (placebo nonresponders) and normal controls. The question of whether differences in 5-HT uptake site density and $5-\mathrm{HT}_{2}$ receptor density values between depressed patients and controls represent trait or state phenomena remains unsettled, with evidence in the literature on both sides of the question (see review by Bunney et al. 1986; Meltzer and Arora 1988). An interesting comparison between monozygotic and dizygotic twins revealed a significantly greater intra-class correlation between 5-HT uptake site density in monozygotic than in dizygotic twins, suggesting that 5-HT uptake site density may be heritable (Meltzer and Arora 1988).

An unexpected finding of our study was the higher 5-HT affinity values in both placebo responders and placebo nonresponders than in normal controls. Since the platelet collection took place at least 3 weeks after any known exposure to psychotropic medication, it is unlikely that these affinity differences reflect competitive binding of residual antidepressant drugs. Furthermore, there was no group difference in pretreatment drug-free interval between placebo responders (mean 21.6 weeks) and placebo nonresponders (mean 19.6 weeks). The fact that we did not find a significant difference among the three groups in platelet $5-\mathrm{HT}_{2}$ receptor density values was not surprising given the fact that we have previously (Sheline et al. 1995) found a trend only toward a difference between depressed patients and normals, although other groups (Arora and Meltzer 1989; Biegon et al. 1990; Pandey et al. 1990) have found significant differences. Of course, another factor may be the low correlation between platelet $5-\mathrm{HT}_{2}$ values obtained on admission and at washout. This could have obscured a potential group difference.

Determination of platelet 5-HT uptake site density values in patients about to participate in controlled antidepressant drug trials may offer an opportunity to identify and screen out patients likely to respond to placebo and to lessen the power of the drug trial. However, it is not clear whether patients who respond to placebo during a 7- to 10-day washout are a subset of patients who may respond to placebo over longer periods or whether they constitute a separate group. As discussed, a number of clinical differences have been identified between placebo responders and nonresponders after 6 to 12 weeks of treatment. The literature on patients who respond to placebo during the usual 7- to 10-day washout period is much more limited.

Quitkin et al. (1991, 1993a, 1993b) have suggested that placebo responses occurring early in 6-and 12 -week clinical trials are more likely to be the true effect of 
placebo, whereas more gradual "placebo" responses that occur throughout the trial are more likely to be spontaneous remissions. It is possible that our placebo responders are similar to the patients with abrupt early responses described by Quitkin et al. In future studies we intend to make platelet 5 -HT measurements in patients who appear to respond to placebo over the usual time course of antidepressant drug response to determine whether placebo responders of this type and nonresponders can also be differentiated. We hope that regardless of whether the patients have a placebo response early or late in treatment, biochemical characteristics such as platelet 5-HT uptake site density values can be used to identify them.

\section{REFERENCES}

Arora RC, Meltzer HY (1989): Increased serotonin 2 (5- $\left.\mathrm{HT}_{2}\right)$ receptor binding as measured by $3 \mathrm{H}$-lysergic acid diethylamide (3H-LSD) in the blood platelets of depressed patients. Life Sci 44:725-734

Biegon A, Grinspoon A, Blumenfeld B, Bleich A, Apter A, Mester R (1990): Increased serotonin 5- $\mathrm{HT}_{2}$ receptor binding on blood platelets of suicidal men. Psychopharmacol 100:165-167

Brown WA, Dornseif BE, Wernicke JF (1988): Placebo response in depression: A search for predictors. Psychiatr Res 26:259-264

Brown WA, Johnson MF, Chen M-G (1992): Clinical features of depressed patients who do and do not improve with placebo. Psychiatr Res 41:203-214

Bunney WE, Garland-Bunney B, Patel SB (1986): Biological markers in depression. Psychopathology 19(2):72-78

Cook EH, Fletcher KE, Wainwright M, Maks N, Yan S, Leventhal BL (1994): Primary structure of the human platelet serotonin $5-\mathrm{HT}_{2 \mathrm{a}}$ receptor: Identity with frontal cortex serotonin 5- $\mathrm{HT}_{2 \mathrm{a}}$ receptor. J Neurochem 63:465-469

Fairchild CJ, Rush AJ, Vasavada N, Giles DE, Khatami M (1986): Which depressions respond to placebo? Psychiatr Res 18:217-226

Faustmann WO, Faull KF, Whiteford HW, Bochert C, Csernansky JG (1990): CSF 5-HIAA, serum cortisol and age differentially predict vegetative and cognitive symptoms in depression. Biol Psychiatr 27:311-318

Freeman AM, Stankovic SMI, Bradley RJ, Zhang GZ, Libb JW, Nemeroff CB (1993): Tritiated platelet imipramine binding and treatment response in depressed outpatients. Depression 1:20-23

Gross-Isseroff R, Israel M, Biegon A (1989): Autoradiographic analysis of tritiated imipramine binding in the human brain post-mortem: Effects of suicide. Arch Gen Psychiatry 46:237-241

Grunbaum A (1985): Explication and implications of the placebo concept. In White L, Tursky B, Schwartz G (eds), Placebo: Theory, Research and Mechanisms, New York, Guilford Press, p 9
Hamilton M (1960): A rating scale for depression. J Neurol Neurosurg Psychiatry 23:56-62

Khan A, Dager SR, Cohen S, Avery DH, Scherzo SA, Dunner DC (1991): Chronicity of depressive episode in relation to antidepressant-placebo response. Neuropsychopharmacol 4:125-130

Lesch K-P, Wolozin BL, Murphy DL, Riederer P (1993): Primary structure of the human platelet serotonin uptake site: Identity with the brain transporter. J Neurochem $60: 2319-2322$

Mann JJ, McBride PA, Brown RP, et al. (1992): Relationship between central and peripheral serotonin indexes in depressed and suicidal psychiatric inpatients. Arch Gen Psych 49:442-446

Marcusson J, Ross SB (1990): Binding of some antidepressants to the 5-hydroxytryptamine transporter in brain and platelets. Psychopharmacol 102:145-155

Meltzer HY, Arora RC (1988): Genetic control of serotonin uptake in blood platelets: A twin study. Psychiatr Res 24:263-269

Meltzer HY, Lowy MT (1987): The serotonin hypothesis of depression. In Meltzer HY (ed), Psychopharmacology, The Third Generation of Progress, New York, Raven, pp 513-526

Montgomery SA, Asberg M (1979): A new depression rating scale designed to be sensitive to change. Br J Psychiatry 134:382-389

Pandey GN, Pandey SC, Janicak PG, Merks RC, Davis JM (1990): Platelet serotonin-2 receptor binding sites in depression and suicide. Biol Psychiatry 28:215-222

Peselow E, Sanfilipo M, Difiglia C, Fieve R (1992): Melancholic/endogenous depression and response to somatic treatment and placebo. Am J Psychiatry 149:1324-1334

Quitkin FM, Rabkin J, Ross D (1984): Identification of a true drug response to antidepressants: Use of pattern analysis. Arch Gen Psychiatry 41:782-786

Quitkin FM, Rabkin JG, Stewart JW, McGrath PJ, Harrison W, Ross DC, Tricamo E, Fleiss J, Markowitz J, Klein DT (1991): Heterogeneity of clinical response during placebo treatment. Am J Psychiatry 148:193-196

Quitkin FM, Stewart JW, McGrath PJ, Nunes E, OcepekWelikson K, Tricamo E, Rabkin JG, Ross D, Klein DF (1993a): Loss of drug effects during continuation therapy. Am J Psychiatry 150:562-565

Quitkin FM, Stewart JW, McGrath PJ, Nunes E, OcepekWelikson K, Tricamo E, Rabkin JG, Ross D, Klein DF (1993b): Further evidence that a placebo response to antidepressants can be identified. Am J Psychiatry 150: 566-570

Rabkin JG, Stewart JW, McGrath PJ, Markowitz JS, Harrison W, Quitkin FM (1987): Baseline characteristics of 10-day placebo washout responders in antidepressant trials. Psychiatr Res 21:9-22

Ramamoorthy S, Bauman AL, Moore KR, Han H, Yang-Feng, Chang AS, Ganapathy V, Blakely RD (1993): Antidepressant and cocaine-sensitive human serotonin transporter: Molecular cloning, expression, and chromosomal localization. Proc Natl Acad Sci USA 90:2542-2546

Shapiro AK, Morris L (1978): The placebo effect in medical 
and psychological therapies. In Garfield S, Bergen A (eds), Handbook of Psychotherapy and Behavior Change, ed 2, New York, Wiley, p 369

Sheline YI, Bardgett ME, Jackson JL, Newcomer JW, Csernansky JG (1995): Platelet serotonin markers and depressive symptomatology. Biol Psychiatry 37:442-447

Stanley M, Virgilio J, Gershon S (1982): Tritiated imipramine binding sites are decreased in the frontal cortex of suicides. Science 216:1337-1339

Trivedi MH, Rush J (1994): Does a placebo run-in or a placebo treatment cell affect the efficacy of antidepressant medications? Neuropsychopharmacol 11:33-43

Turner J, Gallimore R, Fox-Henning C (1980): An annotated bibliography of placebo research. JSAS Catalog of selected documents in Psychology 10 no. 2063

Zammit GK, Rosenbaum AH, Stokes P, Davis J, Zorick F, Roth T (1988): Biological differences in endogenous depressive placebo responders versus nonresponders: Dexamethasone suppression test and sleep EEG data. Biol Psychiatry 24:97-101 